\title{
Secondary Central Nervous System Lymphoma
}

National Cancer Institute

\section{Source}

National Cancer Institute. Secondary Central Nervous System Lymphoma. NCI

Thesaurus. Code C87797.

A non-Hodgkin or Hodgkin lymphoma that has metastasized to the central nervous system following the initial presentation in another nodal or extranodal site. 